\title{
Hyperlipidemia Affects Tight Junctions and Pump Function in the Corneal Endothelium
}

Jinghua Bu, ${ }^{*}$ Jingwen $\mathrm{Yu}{ }^{*}$ Yang $\mathrm{Wu},{ }^{*}$ Xiaoxin Cai, ${ }^{*}$ Kechun $\mathrm{Li},,{ }^{\ddagger}$ Liying Tang, ${ }^{*}$ Nan Jiang, ${ }^{*}$ M. Vimalin Jeyalatha, Minjie Zhang, ${ }^{*}$ Huimin Sun, ${ }^{*}$ Hui He, ${ }^{*}$ Andrew J. Quantock, ${ }^{\S}$ Yongxiong Chen, ${ }^{*}$ Zuguo Liu, ${ }^{*}$ and Wei $\mathrm{Li}^{*}$

From the Department of Ophthalmology, *Xiang'an Hospital of Xiamen University, Fujian Provincial Key Laboratory of Ophthalmology and Visual Science, Eye Institute of Xiamen University, School of Medicine, Xiamen University, Xiamen, China; the Xiamen Branch, ${ }^{\dagger}$ Zhongshan Hospital, Fudan University, Xiamen, China; the Datong Middle School, ${ }^{\ddagger}$ Xiamen, China; the School of Optometry and Vision Sciences, ${ }^{\S}$ Cardiff University, Cardiff, United Kingdom; and the Xiamen University Affiliated Xiamen Eye Center, ${ }^{\top}$ Xiamen, China

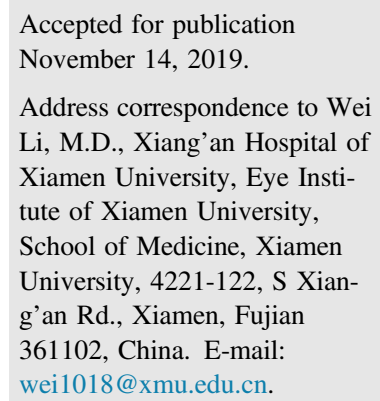

\begin{abstract}
Hyperlipidemia impacts on various diseases, such as atherosclerosis, hypertension, and diabetes mellitus. However, its influence, if any, on ocular tissues is largely unknown. Herein, we developed hyperlipidemic murine models by feeding 4-week-old male wild-type mice with a high-fat diet and apolipoprotein $\mathrm{E}$ knockout $\left(A p \mathrm{AE}^{-/-}\right)$mice with a high-fat diet or standard diet to investigate the corneal endothelial change under hyperlipidemic conditions. Oil Red 0 staining showed an accumulation of lipid droplets in corneal endothelial cells (CECs) of hyperlipidemic mice. Other manifestations included a reduced cell density and distorted cell morphology, a disruption of the endothelial cell tight junctions and adhesion junctions, a reduced number of surface microvilli, down-regulation of $\mathrm{Na}^{+}-\mathrm{K}^{+}$ATPase expression and function, activation of oxidative stress, changes in mitochondrial ultrastructure, and increased apoptosis. CEC recovery after injury, moreover, was diminished in hyperlipidemic mice; and high palmitate levels were found in the aqueous humor. In vitro hyperlipemia model, moreover, was found to be associated with dose-dependent CEC cytotoxicity, altered cell morphology, reduced pump function, and an induction of oxidative stress, leading to functional and pathologic changes in the corneal endothelium. (Am J Pathol 2020, 190: 563-576; https://doi.org/10.1016/j.ajpath.2019.11.008)
\end{abstract}

Hyperlipidemia is characterized by increased levels or deposition of circulating lipid, ${ }^{1}$ and is considered to be a major risk factor in atherosclerosis, cardiovascular diseases, hypertension, and diabetes mellitus. ${ }^{2-4}$ Among these systemic diseases, hyperlipidemia-induced vascular pathologies are common, ${ }^{5,6}$ in which vascular endothelial cells are at risk because hyperlipidemia can induce inflammasome activation $^{7}$ and endoplasmic reticulum stress. ${ }^{8}$ With regard to the eye, lipid deposition has been reported in the cornea (a condition known clinically as corneal arcus) during hyperlipidemia, ${ }^{9}$ and this has also been demonstrated in hyperlipidemic animal models in which the regression of corneal arcus is seen after the cessation of diet-induced hyperlipidemia. ${ }^{10}$ Similarly, lipid keratopathy is characterized by a deposition of lipids in the stroma and is often accompanied with vascularization. ${ }^{11}$ It has also been suggested that lipid keratopathy is more prevalent in patients with higher circulating cholesterol levels, ${ }^{12}$ and it is the case that women are more vulnerable to lipid keratopathy than men because of their higher high-density lipoprotein levels. ${ }^{13}$ To date, however, there is no evidence with regard to the possible effect of hyperlipidemia on the physiology of corneal endothelial cells (CECs).

As previously reported, a high-fat diet (HFD) can increase circulating lipid levels and is widely used to induce hyperlipidemia in murine models. ${ }^{14,15}$ Apolipoprotein $\mathrm{E}$ (ApoE) is a cholesterol carrier that aids the transport of

\footnotetext{
Supported in part by the National Key R\&D Program of China grants 2018 YFA0107301 (W.L.) and 2018YFA0107304 (Z.L.); and the National Natural Science Foundation of China grants 81770894 (W.L.), 81470602 (W.L.), 81970773 (W.L.), 81330022 (Z.L.), and 81570818 (Y.C.).

J.B., J.Y. and Y.W. contributed equally to this work.

Disclosures: None declared.
} 
lipids and fat-soluble vitamins in the body, ${ }^{16}$ and in the cornea, its abnormal deposition has been associated with some corneal pathologic conditions. ${ }^{11,17}$ Accordingly, elevated serum cholesterol levels have been noted in apolipoprotein E knockout $\left(A p o E^{-/-}\right)$mice, which during HFD feeding exhibit an extreme hypercholesterolemic phenotype compared with mice fed with a standard diet (SD). ${ }^{18} \mathrm{ApoE}^{-/-}$mice, therefore, represent a valuable resource to support research into hyperlipidemia. ${ }^{19}$ To investigate the potential effect of hyperlipidemia on the corneal endothelium, CECs were studied in vivo and in an ex vivo cell culture model with a focus on lipid accumulation, cell morphology, tight junction formation, pump function, oxidative damage, and mitochondrial health. Pathologic changes of CECs were discovered under various degrees of hyperlipidemia via feeding $A p o E^{-/-}$and wildtype (WT) mice with either an SD or HFD, indicating that hyperlipidemia compromises CEC function via an oxidative stress pathway.

\section{Materials and Methods}

\section{Antibodies}

The following antibodies were used in this study: anti-zonula occludens protein 1 (ZO-1; QA21310; Life Technologies, Carlsbad, CA), anti-N-cadherin (13116S; Cell Signaling Technology, Danvers, MA), anti- $\mathrm{Na}^{+}-\mathrm{K}^{+}$-ATPase (ab76020; Abcam, Cambridge, UK), anti-4-hydroxynonenal (4-HNE; ab46545; Abcam), anti-NADPH oxidase 4 (NOX4; ab13303; Abcam), anti-8-dihydroxy-2'-deoxyguanosine (8OHdG; sc-393871; Santa Cruz Biotechnology, Dallas, TX), anti-Tom20 (11802-1-AP; Proteintech, Rosemont, IL), and anti-Tim23 (11123-1-AP; Proteintech). The secondary antibodies were Alexa Fluor 594-conjugated IgG (A11508; Invitrogen, Carlsbad, CA) and Alexa Fluor 488-conjugated IgG (A11055; Invitrogen).

\section{Animals}

$A p o E^{-/-}$mice on a C57BL/6 background and wild-type C57BL/6 mice were obtained from Beijing Vital River Laboratory Animal Technology Co, Ltd (Beijing, China). New Zealand white rabbits were purchased from Shanghai SLAC Laboratory Animal Center (Shanghai, China). All animals were kept in standard pathogen-free environment with alternate 12-hour light-dark cycles (8:00 AM to 8:00 $\mathrm{PM})$. In vitro cell culture experiments used corneal endothelia from rabbits rather than mice to avoid the need to sacrifice large numbers of animals to ascertain optimal cultivation protocols, which tend to be species specific. All animal studies were performed in accordance with the Association for Research in Vision and Ophthalmology Statement for the Use of Animals in Ophthalmic and Vision Research and approved by the Animal Ethical Committee of Xiamen University.

\section{Hyperlipidemia Animal Model}

At 4 weeks of age, WT and $A p o E^{-/-}$mice were fed with either an SD (1022; Beijing HFK Bioscience, Beijing, China; $10 \mathrm{kcal} \%$ fat) or an HFD (D12492; Research Diets, New Brunswick, NJ; 60 kcal\% fat). After 16 weeks of receiving the respective diet, mice were sacrificed by cervical dislocation.

\section{Plasma Cholesterol Measurements}

Before SD or HFD feeding commenced and after 16 weeks of diet feeding, blood was collected from 16 hours fasted mice $(n=7)$ by cardiac puncture at the time of sacrifice, after which the fasting glucose concentration was measured using a glucose analyzer (ACCU-CHEK; Roche, Basel, Switzerland). Blood was similarly collected from 6 to 8 hours fasted mice $(n=7)$, after which serum total cholesterol was measured enzymatically using a commercially available kit (ab65390; Abcam).

\section{Oil Red 0 Staining}

Oil Red O staining was performed to evaluate lipid accumulation in CECs. Corneal whole-mount tissues were fixed in $4 \%$ paraformaldehyde for 10 minutes, washed in phosphate-buffered saline (PBS) for 5 minutes, and then stained for 10 minutes in freshly prepared Oil Red O solution. After rinsing with PBS for 5 minutes, the tissues were mounted in $90 \%$ glycerol and observed under light microscope (Eclipse 50i; Nikon, Tokyo, Japan). Three samples from each group were used to conduct Oil Red O corneal endothelial whole-mount staining. Five areas with the same surface area in each sample were chosen to quantify and analyze staining intensity, avoiding the folded area. The mean staining intensity was measured by image analysis software (NIS Elements version 4.1; Nikon, Melville, NY).

\section{In Vivo Confocal Microscopy}

After general anesthesia, mice corneas $(n=7)$ were examined with a laser-scanning in vivo confocal microscope with a corneal imaging module (HRT3-RCM; Heidelberg Engineering, Heidelberg, Germany). Briefly, a drop of transparent carbomer gel (Alcon Laboratories, Fort Worth, TX) was placed on the microscope objective lens with a sterile disposable plastic cap (Tomocap; Heidelberg Engineering) affixed over the gel-coated lens. The center of the cap was applanated onto the central cornea by adjusting the controller, and the central corneal endothelium was examined. More than 30 in vivo digital images were captured once the CEC was located. The cell counting function of the HRT3-RCM machine software (Heidelberg Eye Explorer version 1.9.10.0; Heidelberg Engineering, Heidelberg, Germany) was used to perform corneal endothelial cell counting (Supplemental Video S1). To determine hexagonality, the 
number of cell sides directly apposed to adjacent cells within the endothelial mosaic of each sample were counted; hexagonal cells were marked and counted to calculate the percentage of hexagonal cells. For these measurements, three to four selected images in each eye were analyzed. All operations were performed by a single investigator (M.Z.) masked to the experimental conditions.

\section{Murine Corneal Cryowounding Model}

CEC damage was performed as previously described with modifications. ${ }^{20}$ In brief, mice were anesthetized with i.p. injection of $0.2 \%$ chloral hydrate, after which the ocular surface was further anesthetized with a drop of $0.4 \%$ oxybuprocaine hydrochloride (Santen Pharmaceutical, Osaka, Japan) before surgery. A stainless steel probe cooled with liquid nitrogen was applied to central cornea of right eye of the mice $(n=7)$ for 30 seconds. Ofloxacin eye ointment (Santen Pharmaceutical) was instilled in each eye twice a day after the procedure. During the follow-up, corneas were observed under a slit-lamp microscope (Kanghua Science \& Technology Co, Ltd, Chongqing, China), and corneal thickness at different time points was measured by in vivo confocal microscopy. Animals were sacrificed 7 days after the freeze injury to assess the status of the corneal endothelium.

\section{Corneal Endothelium Ultrastructure Examination}

Corneas from experimental groups ( $n=3$ for each group) were fixed in a mixture of $2.5 \%$ glutaraldehyde and $4 \%$ paraformaldehyde in PBS ( $\mathrm{pH} 7.4$ ) at $4^{\circ} \mathrm{C}$ for 2 hours. They were cut into $4 \times 2$-mm sized pieces, without touching the endothelium, and further embedded, sliced, and stained. The ultrastructure of corneal endothelium was examined and imaged using scanning electron microscope (JSM6390LV; JEOL, Tokyo, Japan) or transmission electron microscopy (JEM2100HC; JEOL). Mitochondria with cristae abnormalities and vacuoles were considered to be abnormal. Mitochondria in six to eight transmission electron microscopy images taken from each cornea at $\times 10,000$ magnification were counted, and the ratio of the number of abnormal mitochondria/the total number of mitochondria was calculated.

\section{Aqueous Humor Extraction}

After general anesthesia, a drop of $0.4 \%$ oxybuprocaine hydrochloride was used to anesthetize the ocular surface before aqueous humor procurement. Aqueous humor was obtained from the anterior chamber of mice via a paracentesis using a sharp capillary straw (Supplemental Video $\mathrm{S} 2$ ). The samples were immediately frozen at $-80^{\circ} \mathrm{C}$ after extraction, and palmitate levels were measured by the use of a high-performance liquid chromatography-tandem mass spectrometry system, as described previously. ${ }^{21}$ A total of 4 to $5 \mu \mathrm{L}$ of aqueous humor was collected per mouse $(n=18)$, and three samples were used in each group (one sample consisted of pooled aqueous humor from six mice). Because the amount of aqueous humor from one mouse is small, samples from six mice were pooled within each group to reach the minimum volume required for HPLC analysis. The total amount of pooled aqueous humor was thus approximately $25 \mu \mathrm{L}$ in each group.

\section{Primary rCEC Culture}

Rabbit, rather than mouse, CECs (rCECs) were used for the ex vivo cell culture experiments as culture protocols are well established in our laboratory and in the published literature. This is not the case for mouse CECs. Rabbit corneas $(n=$ 18) were harvested after sacrificing the animals, and the endothelial cells with Descemet membrane attached were mechanically separated from the corneal stroma under a dissecting microscope. These specimens were digested in 1 $\mathrm{mg} / \mathrm{mL}$ collagenase I in supplemented hormonal epithelial medium for 16 hours to digest the Descemet membrane, as previously reported. ${ }^{20}$ Supplemented hormonal epithelial medium was prepared with equal volume of HEPESbuffered Dulbecco's modified Eagle's medium and Ham's F12 supplemented with 5\% fetal bovine serum, $0.5 \%$ dimethyl sulfoxide, $2 \mathrm{ng} / \mathrm{mL}$ mouse epidermal growth factor (Life Technologies), $5 \mu \mathrm{g} / \mathrm{mL}$ insulin, $5 \mu \mathrm{g} / \mathrm{mL}$ transferrin, 5 $\mathrm{ng} / \mathrm{mL}$ selenium, $0.5 \mu \mathrm{g} / \mathrm{mL}$ hydrocortisone, $50 \mu \mathrm{g} / \mathrm{mL}$ gentamicin, and $1.25 \mu \mathrm{g} / \mathrm{mL}$ amphotericin B. After digestion, rCECs were dispersed into a cell suspension and cultured in supplemented hormonal epithelial medium at $37^{\circ} \mathrm{C}$ with $5 \% \mathrm{CO}_{2}$. The medium was changed every 3 days. Primary rCECs at passage 0 were used after reaching confluence.

\section{Palmitate Preparation}

Palmitate (Sigma-Aldrich, St. Louis, MO) was dissolved in $0.1 \mathrm{~mol} / \mathrm{L} \mathrm{NaOH}$ (shaken in water bath at $75^{\circ} \mathrm{C}$ for 30 minutes) and diluted 1:1 in preheated $1 \times$ PBS containing $40 \%$ (w/v) bovine serum albumin (BSA; Sigma-Aldrich) to give a concentration of $20 \mathrm{mmol} / \mathrm{L}$ (stock palmitate solution). The BSA should be free of fatty acids and endotoxins. Therefore, the stock palmitate solution was passed through a $0.2-\mu \mathrm{m}$ filter and diluted in supplemented hormonal epithelial medium to obtain concentration of 0 to 1000 $\mu \mathrm{mol} / \mathrm{L}$ for use.

\section{Cell Viability Assay}

Cell viability to evaluate cytotoxicity of palmitate on rCECs was assessed by the use of a Cell Counting Assay Kit- 8 (Dojindo Molecular Technologies, Kumamoto, Japan), according to the manufacturer's instructions. CECs were seeded at density of $1 \times 10^{4}$ cells per well in 96 -well plates overnight and were treated with palmitate at varying concentrations ( 0 to $1000 \mu \mathrm{mol} / \mathrm{L}$ ). BSA was used as vehicle control. After 24 
hours in culture, the medium was replaced by Cell Counting Assay Kit- 8 constituted media and incubated for 4 hours at $37^{\circ} \mathrm{C}$ in the dark. Absorbance at $450 \mathrm{~nm}$ was measured using a microplate reader (Bio-Tek, Winooski, VT).

\section{Immunofluorescence Staining}

Cryosections (5 $\mu \mathrm{m}$ thick) of mouse eyes, corneal whole mounts, or cultured cells were fixed in acetone at $-20^{\circ} \mathrm{C}$ for 10 minutes. The samples were washed three times with PBS for 10 minutes per wash and then incubated in $0.2 \%$ Triton $\mathrm{X}-100$ for 10 minutes. After rinsing the sections three times in PBS for 5 minutes, they were blocked with $2 \%$ BSA for 1 hour at room temperature and incubated with anti-ZO-1 (1:100), anti- $\mathrm{N}$-cadherin $(1: 100)$, anti- $\mathrm{Na}^{+}-\mathrm{K}^{+}$-ATPase (1:100), anti-4-HNE (1:200), anti-8-OHdG (1:50), antiTom20 (1:100), or anti-Tim23 (1:100) primary antibodies overnight at $4{ }^{\circ} \mathrm{C}$. The next day, samples were washed three times in PBS for 10 minutes and incubated with secondary antibodies Alexa Fluor 594-conjugated IgG (1:300) or Alexa Fluor 488-conjugated IgG (1:300) for 1 hour at room temperature in the dark. After three washes in PBS and counterstaining with DAPI (H-1200; Vector, Burlingame, CA), laser confocal scanning microscope (Fluoview 1000; Olympus, Tokyo, Japan) was used to study the immunofluorescence.

\section{Measurement of Mitochondrial Transmembrane Potential}

JC-1 (5, 5', 6, 6'-tetrachloro-1, 1', 3, 3'-tetraethylbenzimidazole-carbocyanide iodide) is a cationic fluorescent dye that, when added to live cells, is only located in mitochondria, and is particularly attracted to those in good physiological condition characterized by a sufficient mitochondrial membrane potential. ${ }^{22}$ Mitochondrial function was assessed by tracking the mitochondrial transmembrane potential through detection of the fluorescent probe, JC-1. Following the manufacturer's instructions (Beyotime, Shanghai, China), CECs cultured in confocal dishes were treated with JC-1 staining solution for 20 minutes at $37^{\circ} \mathrm{C}$ in the dark. Cells were subsequently washed with JC-1 staining buffer twice and observed under a laser scanning confocal microscope (Fluoview 1000).

\section{Measurement of $\mathrm{Na}^{+}-\mathrm{K}^{+}$-ATPase Activity}

The activity of $\mathrm{Na}^{+}-\mathrm{K}^{+}$-ATPase, which is central to the workings of the corneal endothelial pump, was determined by measuring the hydrolysis of ATP. Released inorganic phosphate from ATP was detected using a commercial assay kit (Solarbio, Shanghai, China) in accordance with the manufacturer's instructions. Briefly, CECs cultured in a 6-well plate were collected and lysed in lysis buffer for 2 minutes. Cellular lysates were centrifuged at $8000 \times g$ for 10 minutes to obtain a supernatant, after which $100 \mu \mathrm{L}$ of supernatant from each sample was suspended in a reaction mixture containing $40 \mathrm{mmol} / \mathrm{L} \mathrm{NaCl}, 8 \mathrm{mmol} / \mathrm{L} \mathrm{KCl}, 2$ $\mathrm{mmol} / \mathrm{L} \mathrm{MgCl}_{2}, 5 \mathrm{mmol} / \mathrm{L}$ EGTA, and $20 \mathrm{mmol} / \mathrm{L}$ Tris-HCl, $\mathrm{pH}$ 7.4. Addition of $2 \mathrm{mmol} / \mathrm{L}$ ATP started the reactions, which was terminated after 10 minutes of incubation at $37^{\circ} \mathrm{C}$. The reaction mixtures were then centrifuged at $4000 \times g$ for 10 minutes to get a supernatant, after which $200 \mu \mathrm{L}$ of coloring reagent was mixed with $20 \mu \mathrm{L}$ of the supernatant. After incubation at $40^{\circ} \mathrm{C}$ for 10 minutes, the absorbance was read at $660 \mathrm{~nm}$ using a spectrophotometer (Thermo Fisher Scientific, Waltham, MA) and results were expressed as percentage change compared with control values.

\section{Terminal Deoxynucleotidyl Transferase-Mediated dUTP Nick-End Labeling Assay}

Cell apoptosis detection was performed using the Fluorometric TUNEL System (G3250; Promega, Madison, WI). The whole corneas were rehydrated and incubated with Proteinase K Tris/HCL, pH $7.4(10 \mathrm{mmol} / \mathrm{L})$ for $30 \mathrm{mi}-$ nutes at $37^{\circ} \mathrm{C}$. The whole corneas were washed three times with PBS for 5 minutes each. Then, $50 \mu \mathrm{L}$ of terminal deoxynucleotidyl transferase-mediated dUTP nick-end labeling reaction mixture was added and the corneas were placed in the dark for 1 hour at $37^{\circ} \mathrm{C}$. The whole corneas were rinsed three times with PBS for 5 minutes each, counterstained with DAPI, mounted, and imaged with a microscope (DM2500; Leica Microsystems, Wetzlar, Germany).

\section{Immunohistochemical Staining}

Formalin-fixed eyeballs were processed in paraffin and divided into sections (5 $\mu \mathrm{m}$ thick). Sections were rehydrated and endogenous peroxidase activity was blocked ( $0.3 \%$ hydrogen peroxide in PBS), after which sections were permeabilized with $1 \%$ Triton X-100 for 10 minutes. After rinsing three times with PBS for 5 minutes, the sections were blocked using 2\% BSA for 1 hour at room temperature and incubated with anti-NOX4 (1:200) at $4{ }^{\circ} \mathrm{C}$ overnight. After three rinses with PBS for 10 minutes, the sections were further incubated with biotinylated antirabbit IgG (1:50) for 1 hour, followed by Vectastain Elite $\mathrm{ABC}$ reagent (Vector Laboratories, Burlingame, $\mathrm{CA}$ ) for 30 minutes. The reaction product was then developed with diaminobenzidine for 1 minute, mounted with mounting medium (H-5000; Vector), and examined under a light microscope (Eclipse 50i; Nikon, Tokyo, Japan).

\section{RNA Isolation and Quantitative Real-Time PCR}

Murine corneal endothelia were stripped using toothed forceps, and total RNA was isolated using PicoPure RNA isolation kit (Arcturus, Mountain View, CA). Total RNA from the cultured rCECs was extracted 
Table 1 Mouse Sequences Used for Quantitative Real-Time PCR

\begin{tabular}{lll}
\hline Gene & Sense primer & Antisense primer \\
\hline Actb & 5'-GTGGGAATGGGTCAGAAGGA-3' & 5'-CTTCTCCATGTCGTCCCAGT-3 $^{\prime}$ \\
Tjp1 & 5'-ACGATCTCCTGACCAACGTT-3' & $5^{\prime}$-GCTTTGGGTGGATGATCGTC-3' \\
Ncad & 5'-AGAACAGGGTGGACGTCATT-3' & $5^{\prime}$-CTGTTGGGGTCTGTCAGGAT-3' \\
Atp1b1 & 5'-GCGACATCAATCACGAACGA-3' & $5^{\prime}$-CCCCTCTCTGTAGCCGTAAG-3' \\
\hline
\end{tabular}

Z0-1, zonula occludens protein 1.

using Trizol Reagent (Invitrogen), according to manufacturer's protocol. Seven samples per group for the in vivo studies and five samples per group for the in vitro analyses were used. A sample consisted of the following: pooled corneal endothelia from both eyes of the same animal or one well of cultured CECs seeded in a 24-well plate. RNA was transcribed to cDNA using a reverse transcription kit (PrimeScript RT reagent kit; TaKaRa, Shiga, Japan). Quantitative real-time PCR was performed with a StepOne Real-Time detection system (Applied Biosystems, Foster City, CA) using an SYBR Premix Ex Taq Kit (TaKaRa), according to the manufacturer's instructions. The primer sequences used to amplify specific gene products are listed in Table 1 and Table 2. The amplification program included an initial denaturation step at $95^{\circ} \mathrm{C}$ for 10 minutes, followed by 40 cycles of $95^{\circ} \mathrm{C}$ for 10 seconds and $60^{\circ} \mathrm{C}$ for 30 seconds. Subsequently, a melt curve analysis was performed to access amplification specificity. Differential gene expression was calculated according to the comparative threshold cycle $\left(\mathrm{C}_{\mathrm{T}}\right)$ method and normalized to $\beta$-actin expression as an internal control.

\section{Statistical Analysis}

Statistical analysis was performed with SPSS 16.0.0 (SPSS Inc., Chicago, IL). All summary data are reported as means \pm SD. Statistical analysis was performed with unpaired $t$-test for two-group comparisons or one-way analysis of variance for more than two group comparisons using GraphPad Prism 6.0 software (GraphPad Software, Inc., San Diego, CA). $P<0.05$ was considered statistically significant.

\section{Results}

ApoE Deficiency and HFD Induce Hyperlipidemia and Lipid Deposition in CECS

Body weight and blood lipid levels of 4-week-old ApoE $E^{-/-}$ mice were significantly higher compared with those of age-matched WT mice, whereas the plasma glucose concentrations were similar (Supplemental Figure S1). Body weight increased in WT mice after HFD feeding (WT+HFD; $\mathrm{WH}$ ) for 16 weeks, compared with the body weight of WT mice with an SD (WT+SD; WS). $A p o E^{-/-}$mice fed with SD $\left(A p o E^{-/}+\mathrm{SD} ; \mathrm{AS}\right)$ also showed increased body weight compared with WS mice and had similar body weight as WH mice. $A p o E^{-/-}$mice fed with an $\operatorname{HFD}\left(A p o E^{-/-}+\mathrm{HFD} ; \mathrm{AH}\right)$ showed a significant body weight increase compared with AS mice (Figure 1A). Previously, it was reported that an ApoE mutation and an HFD both influenced total cholesterol level in serum, ${ }^{16}$ and it was found that HFD feeding induced a significant increase of serum total cholesterol in both WT and $A p o E^{-/-}$mice. Compared with WS mice, $A p o E^{-/-}$ mice exhibited a significant increase in total cholesterol when fed with an SD and a much higher level when fed with HFD (Figure 1B). There was no significant differences of fasting blood sugar concentrations among the groups after 16 weeks feeding with an SD or HFD (Figure 1C).

Oil Red O staining of CECs in whole-mount corneal tissues clearly delineated the cell borders of CECs and revealed that there was no lipid deposition in WS mice. However, an accumulation of small lipid droplets was observed in the cytoplasm of CECs in WH mice, with the accumulation being more prominent around the $\mathrm{CEC}$ border

Table 2 Rabbit Sequences Used for Quantitative Real-Time PCR

\begin{tabular}{|c|c|c|}
\hline Gene & Sense primer & Antisense primer \\
\hline$A c t b$ & $5^{\prime}$-CGGCTACAAAGACGGCAAAC- $3^{\prime}$ & $5^{\prime}$-GAACAGGCAGCACATTTGGG-3' \\
\hline Tjp1 & $5^{\prime}$-AGTTTGGCAGCAAGAGATGG-3' & $5^{\prime}$-GCTGTCAGAAAGGTCAGGGA-3' \\
\hline Atp1b1 & 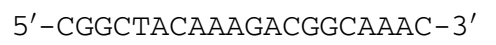 & $5^{\prime}$-GAACAGGCAGCACATTTGGG-3' \\
\hline Nox4 & 5'-TGCTGTATAACCAAGGGCCA-3' & $5^{\prime}$-GGATGAGGCTGCAATTGAGG-3' \\
\hline Nrf2 & $5^{\prime}$-AAGTGGCTGCTCAGAATTGC-3' & $5^{\prime}$-GCTCATCCCGTAACATGCTG-3' \\
\hline Sod1 & $5^{\prime}$-ACCTGGGTAATGTGACTGCA-3' & 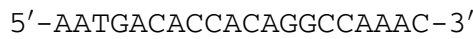 \\
\hline
\end{tabular}



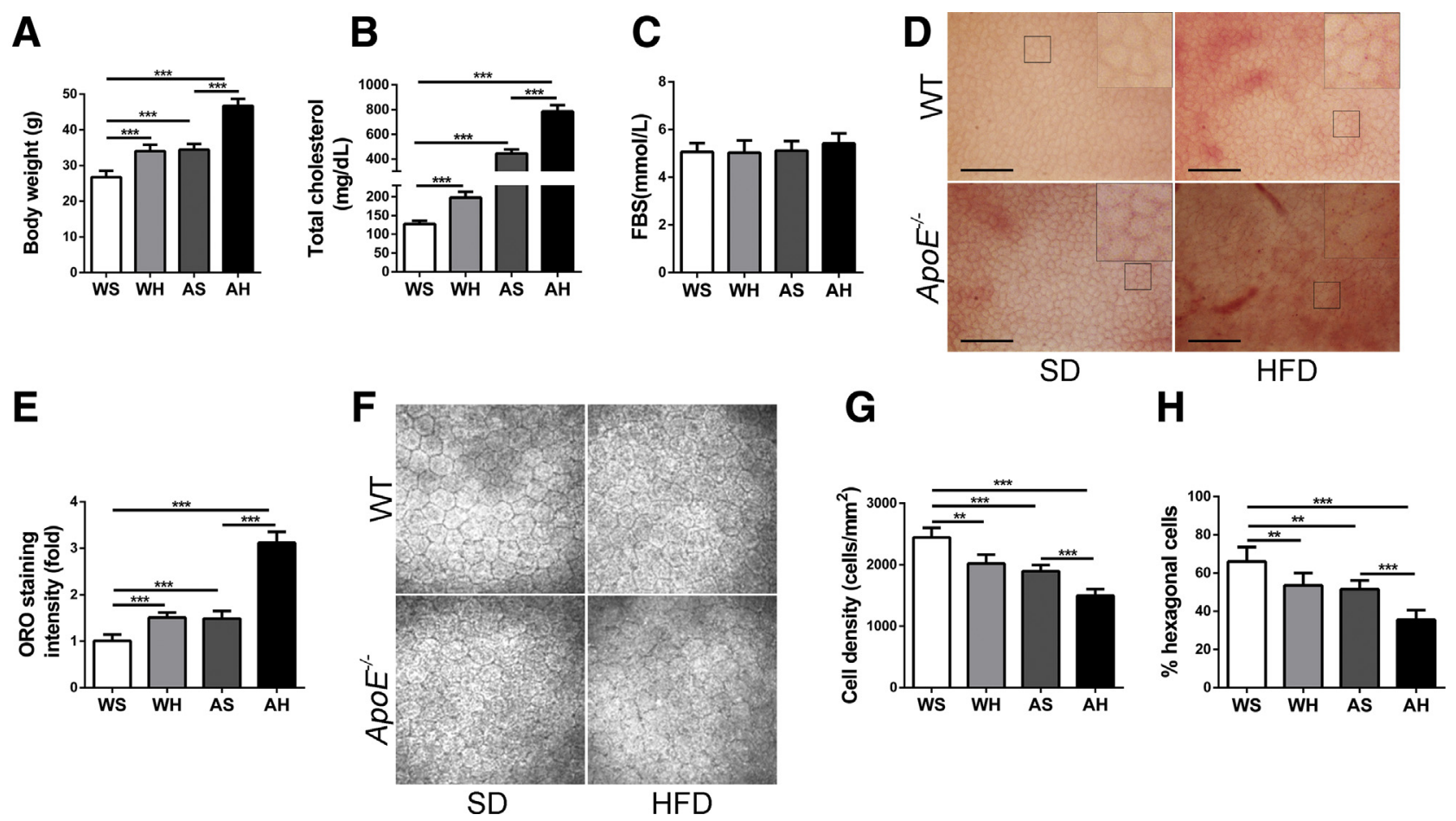

Figure 1 Lipid deposition and altered corneal endothelial cell (CEC) morphology in hyperlipidemic mice. A: Body weight in wild-type (WT) mice fed with standard diet (SD; WS) or high-fat diet (HFD; WH) and $A p o E^{-/-}$mice fed with SD (AS) or HFD (AH). B and C: Total cholesterol (B) and fasting blood sugar (FBS) concentrations (C) in WT mice and $A p o E^{-/-}$mice fed with SD or HFD. D: Representative images of Oil Red 0 (ORO) staining showing lipid droplets between corneal endothelial cells, especially the AH mice. Boxed areas are shown at higher magnification in the insets. E: Oil Red 0 staining intensity in CECs is significantly increased in hyperlipidemia mice. F: Representative images of in vivo confocal microscopy showing disordered cell morphology and cell boundaries in WH, AS, and AH mice. G: Corneal endothelial cell density is significantly decreased in WH, AS, and AH mice. H: The proportion of hexagonal cells significantly decreases in WH, AS, and AH mice. Data are expressed as means $\pm \mathrm{SD}(\mathbf{A}-\mathbf{C}, \mathbf{E}, \mathbf{G}$, and $\mathbf{H}) . n=7(\mathbf{A}-\mathbf{C}$ and $\mathbf{F}-\mathbf{H}) ; n=3(\mathbf{D}$ and $\mathbf{E})$. ${ }^{* *} P<0.01$, $* * * P<0.001$. Scale bars $=50 \mu \mathrm{m}(\mathbf{D})$. Original magnification, $\times 800(\mathbf{F})$.

in AS mice (Figure 1D). Oil Red O staining intensity analysis showed that there was a higher lipid accumulation in the corneal endothelia of WH and AS mice compared with the endothelia of WS mice. The highest lipid accumulation was observed in AH mice (Figure 1E), indicating that hyperlipidemia induces lipid deposition in CECs.

In vivo confocal microscope showed that CECs in WS mice were well organized and exhibited hexagonal shapes in a regular array. In WH and AS mice, numerous CECs lost their typical hexagonal morphology and the cell boundaries became distorted. In addition, after HFD in $A p o E^{-1-}$ mice, severe cell boundary damage and a heterogeneous cell morphology were noted (Figure 1F). Central CEC density in WS mice averaged $2443 \pm 158$ cells $/ \mathrm{mm}^{2}$. In WH mice, average endothelial cell density decreased by $17 \%$ to $2021 \pm 143$ cells $/ \mathrm{mm}^{2}$ compared with WS mice. A small (6\%) decline in CEC density was observed in AS mice $\left(1895 \pm 101 \mathrm{cells} / \mathrm{mm}^{2}\right)$ compared with WH mice, although this difference was insignificant. Overall, a 39\% decrease in mean cell density was observed in AH mice $(1500 \pm 103$ cells $/ \mathrm{mm}^{2}$ ) compared with WS mice (Figure 1G). Morphologically, the endothelial mosaic in WS mice revealed a densely packed polygonal monolayer with $66 \% \pm 8 \%$ hexagonal cells. Both the WH mice and AS mice showed increased irregularity in CEC morphology, with 51\% to
$53 \%$ hexagonal cells, whereas only $36 \%$ hexagonal cells were observed in the corneal endothelium of $\mathrm{AH}$ mice (Figure 1H).

\section{Hyperlipidemia Induces Phenotypic Changes in CECS}

To further determine the pathophysiological changes in CECs during hyperlipidemic stress, whole-mount immunofluorescence staining of ZO- $1, \mathrm{~N}$-cadherin, and $\mathrm{Na}^{+}-\mathrm{K}^{+}$ATPase was performed. The expression of tight junction marker ZO-1 (Figure 2A), N-cadherin (Figure 2B), and pump function marker $\mathrm{Na}^{+}-\mathrm{K}^{+}$-ATPase (Figure 2C) in WS CECs showed integral structures with a clear boundary. In the other three groups, the expression of these markers was sparse, irregular, or absent, especially in $\mathrm{AH}$ mice. The realtime PCR results also showed down-regulated gene expression of ZO-1, N-cadherin, and $\mathrm{Na}^{+}-\mathrm{K}^{+}$-ATPase in WT mice with HFD and in $A p o E^{-/-}$mice with SD or HFD, with the lowest ZO-1, N-cadherin, and $\mathrm{Na}^{+}-\mathrm{K}^{+}$-ATPase gene expression seen in $\mathrm{AH}$ mice (Figure 2, D-F).

On examination by scanning electron microscope, CECs in WS mice appeared flat and hexagonal in shape, with randomly distributed microvilli on the cell surface. In addition, sharply demarcated and interdigitating cellular borders were also observed. In contrast, the number of 

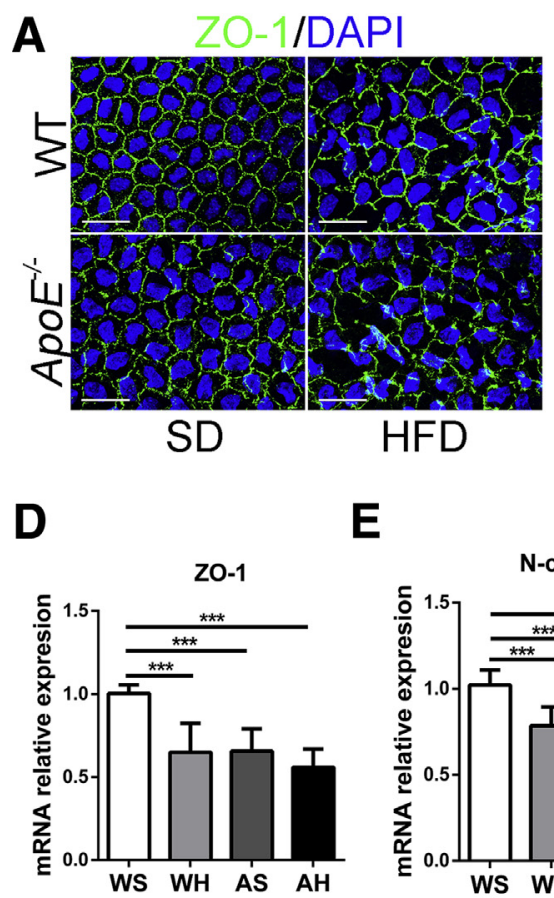

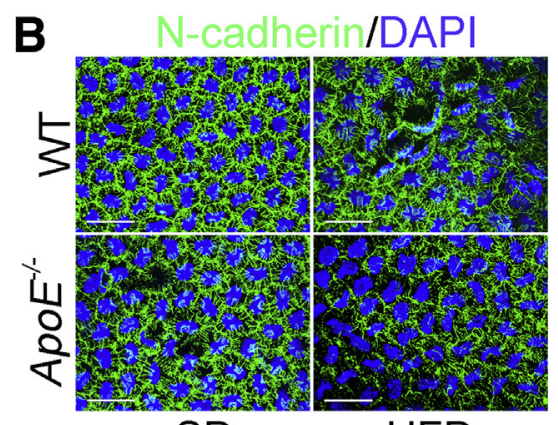

SD HFD

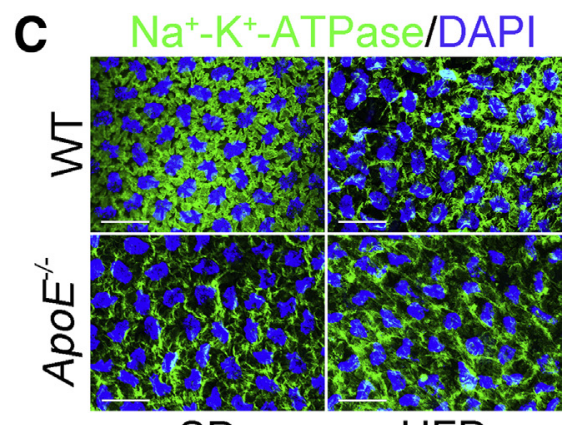

SD

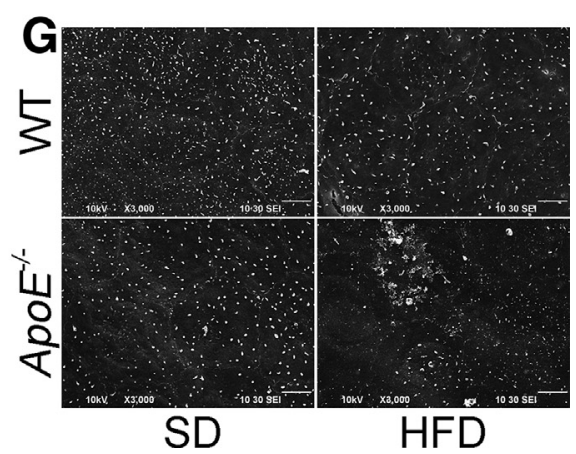

Figure 2 Hyperlipidemia induces disruption of tight junction and down-regulation of pump function in corneal endothelial cells (CECs). A-C: Representative images of zonula occludens protein $1(\mathrm{ZO}-1 ; \mathbf{A}), \mathrm{N}$-cadherin (B), and $\mathrm{Na}^{+}-\mathrm{K}^{+}$-ATPase (C) staining of CECs shows a distorted distribution of these markers in hyperlipidemic mice. D-F: Real-time PCR analysis shows down-regulation of Z0-1, N-cadherin, and Na ${ }^{+} \mathrm{K}^{+}$-ATPase gene expression in hyperlipidemic mice. G: Representative scanning electron microscope images of the apical surface of CECs. The microvilli on CECS are dense and evenly distributed in wild-type (WT) mice fed with standard diet (SD; WS), but more sparse in the other three groups. Data are expressed as means \pm SD (D-F). $n=3$ (A-C and $\mathbf{G})$; $n=7$ (D-F). ${ }^{* *} P<0.01,{ }^{* *} P<0.001$. Scale bars: $50 \mu \mathrm{m}(\mathbf{A}-\mathbf{C}) ; 5 \mu \mathrm{m}(\mathbf{G})$. AH, ApoE ${ }^{-/-}$mice fed HFD; AS, ApoE ${ }^{-/-}$mice fed SD; HFD, high-fat diet; WH, WT mice fed HFD.

microvilli decreased dramatically in the other three groups (ie, WH, AS, and AH) with hyperlipidemia. In AH mice, in particular, the cell boundary between CECs became indistinct in some areas, suggesting disruption of cell-cell tight junction (Figure 2G). Collectively, these data indicated that hyperlipidemia induced phenotypic changes in CECs.

\section{Hyperlipidemia Induces Decompensation of CECs after Endothelial Injury in Mice}

Although the cell density of CECs in hyperlipidemic mice decreased to varying degrees and was accompanied by morphologic changes, corneal edema or other manifestations of corneal endothelial dysfunction were not observed in all the experimental groups (data not shown). Therefore, a corneal cryowounding model was used to observe CEC function and the wound healing response after injury in the control and hyperlipidemic groups. All wounds were generated equally, and fluorescence staining showed mild corneal epithelial staining immediately after the cryowounding (Supplemental Figure S2). The transparency of the cornea was largely restored in the control group at 7 days after injury (Figure 3A). However, corneal edema persisted in experimental groups with hyperlipidemia. Obvious bullous keratopathy was observed in AH mice 3 days after wounding and became more prominent after 7 days, indicating that the corneal endothelial function was compromised (Figure 3A). In vivo confocal microscopy revealed that corneal thickness was significantly higher in hyperlipidemic mice after injury than in WS mice at different time points from day 1 to day 7 (Figure 3B). For all mice, fluorescein staining was seen at low levels (Supplemental Figure S2) and the corneal epithelium recovered from two to three cell layers thick 1 day after wounding to approximately five cell layers thick, 7 days after wounding (Figure 3C). Hematoxylin and eosin staining also showed that there was an intact epithelium and keratocytes present 1 day after wounding in all corneas. One day after wounding, part of the corneal endothelium was detached in WH and AS mice and damaged severely in $\mathrm{AH}$ mice, in contrast to the mild damage seen in the corneas of WS mice (Figure 3C). In the 7 days after wounding, corneal endothelial damage and corneal edema were more severe in hyperlipidemic mice, especially in the AH mice (Figure 3C), consistent with the slit-lamp images (Figure 3A).

\section{Hyperlipidemia Induces 0xidative Stress in Mice CECs}

Previous reports have demonstrated that hyperlipidemia induces oxidative stress in different cell types. ${ }^{23}$ The effect 

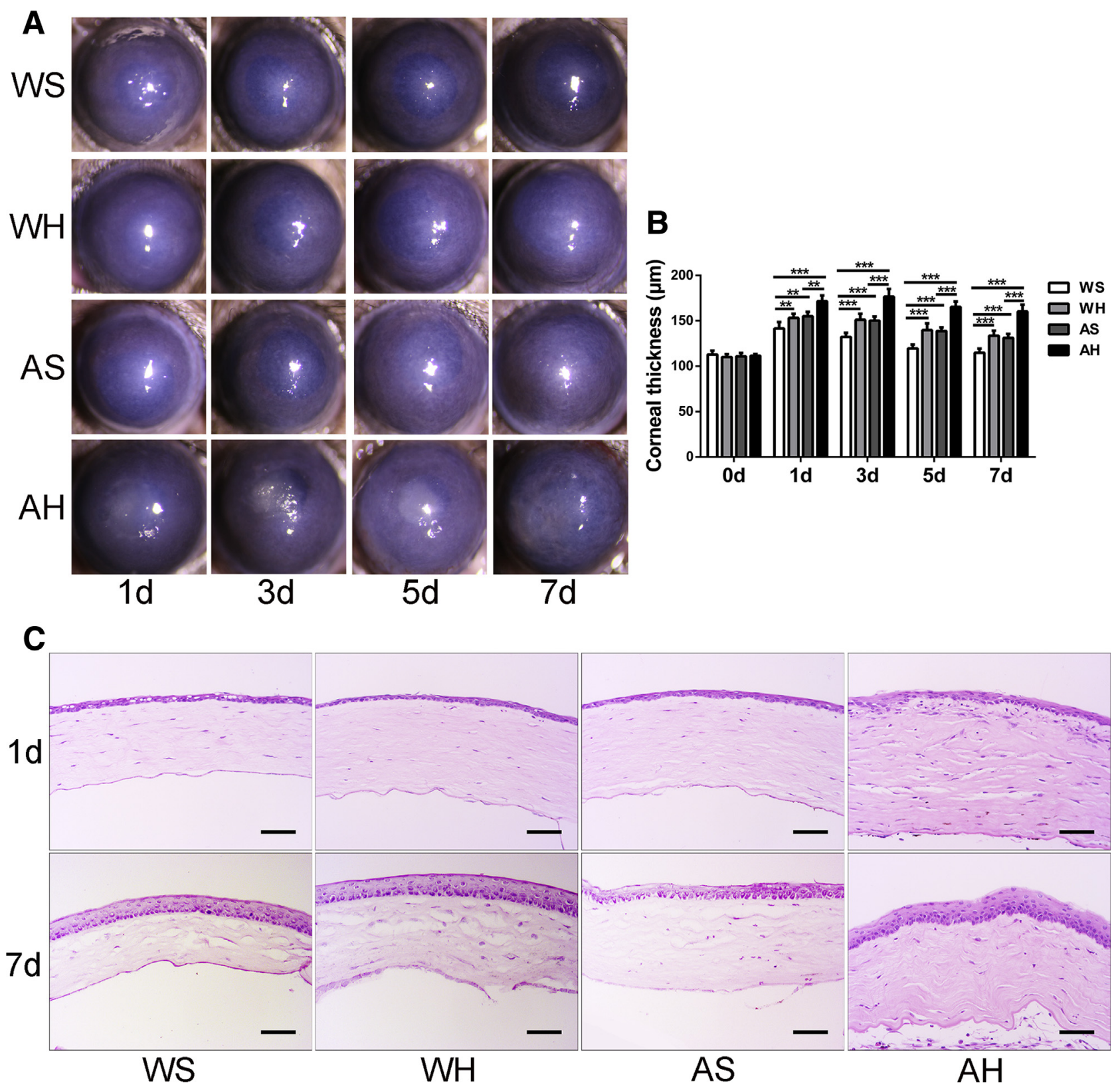

Figure 3 Endothelial injury causes decompensation of corneal endothelial cells (CECs) in hyperlipidemia mice. A: Slit-lamp microscopy images of postinjury CECs showing that corneal transparency was largely restored 7 days after the injury in wild-type (WT) mice fed with a standard diet (SD; WS), with an edematous and less transparent stroma in $\mathrm{ApoE}^{-/-}+$high-fat diet (HFD; $\left.\mathrm{AH}\right)$ mice. B: In vivo confocal microscopy reveals that the cornea is significantly thinner in WS mice after injury than in the corneas of the other three groups of mice. C: Representative images of hematoxylin and eosin staining showing an intact epithelium and keratocytes 1 day after wounding and different degrees of corneal endothelial damage and corneal edema 1 and 7 days after wounding, Data are expressed as means \pm SD (B). $n=7$ (A and B); $n=3(\mathbf{C}) .{ }^{* *} P<0.01,{ }^{* *} P<0.001$. Scale bars $=50 \mu \mathrm{m}(\mathbf{C})$. AS, ApoE ${ }^{-/-}$mice fed SD; WH, WT mice fed HFD.

of hyperlipidemia-induced oxidative stress was studied by conducting immunostaining of classic peroxidation markers 4-HNE, 8-OHdG, and NOX4 in corneal tissue sections of control and hyperlipidemic mice. The results showed that 4HNE (Figure 4A), 8-OHdG (Figure 4B), and NOX4 (Figure 4C) were not expressed in CECs of WS mice. In contrast, these genes were expressed in the other three groups, especially in AH mice. It is well known that mitochondria are vulnerable to oxidative damage, so mitochondrial ultrastructure was examined by transmission electron microscopy. In WS mice, normal mitochondrial structures with an inner membrane characterized by numerous convolutions called cristae were observed. Cristae were swollen and irregular in profile in WH and AS CECs, and not identified at all in mitochondria in $\mathrm{AH}$ mice (Figure 4D). The ratio of dysfunctional mitochondria was significantly elevated in the corneal endothelium in hyperlipidemia mice (Figure 4E), supporting the concept that 
A

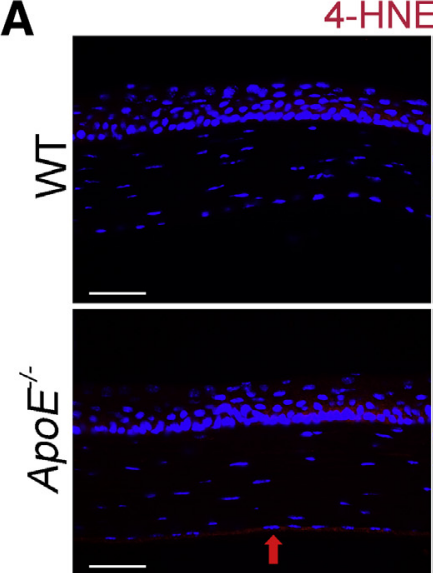

SD

C

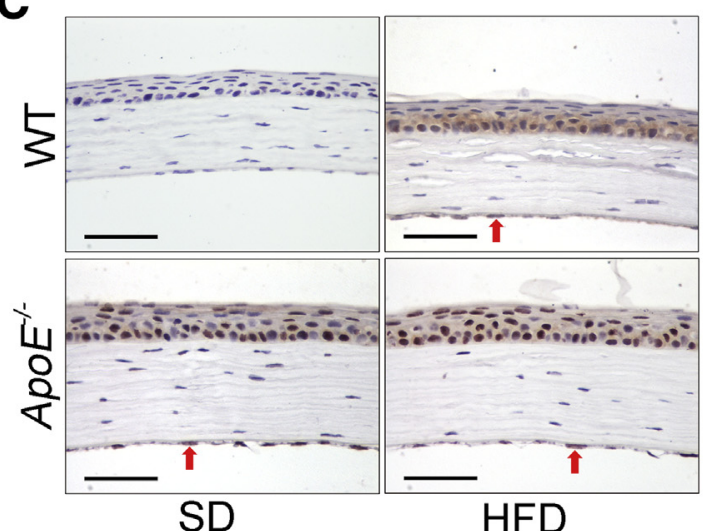

B

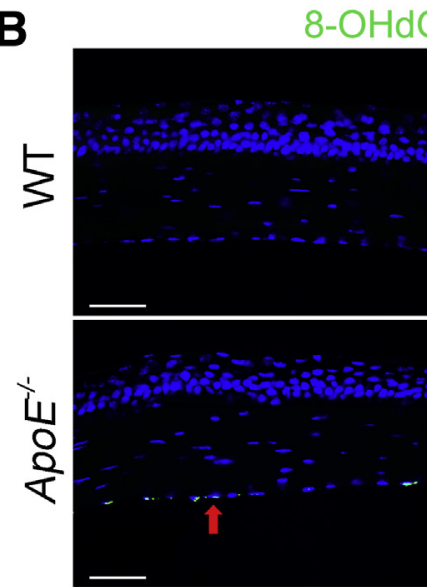

SD

D

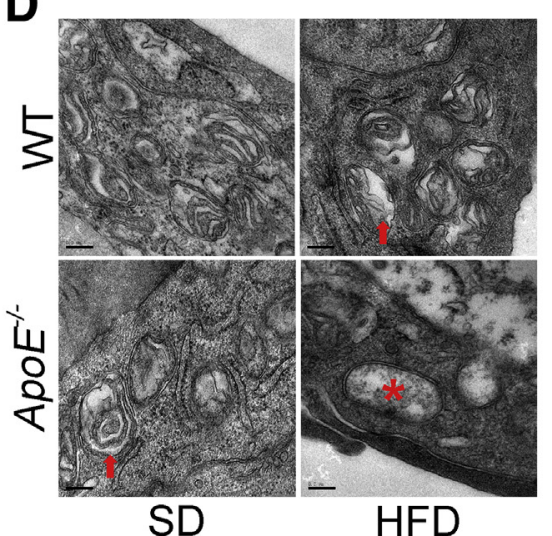

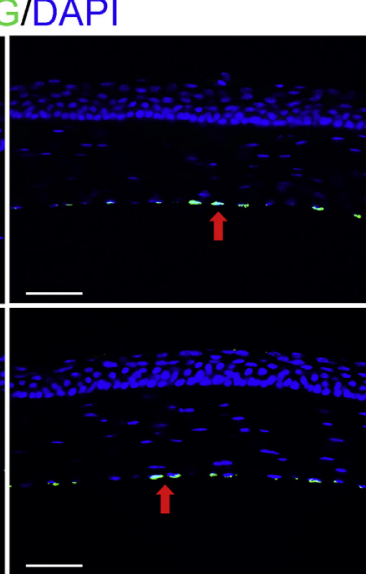

HFD

E

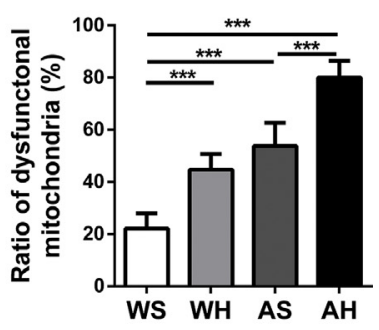

Figure 4 0xidative stress in corneal endothelial cells (CECS) under hyperlipidemic condition. A-C: Representative images of 4-HNE (A), 8-0HdG (B), and NOX4 (C) staining. CECs of wild-type (WT) mice fed with standard diet (SD; WS) mice show a negative expression, with positive expression of these oxidative stress markers in experimental groups. Arrows indicate the positive cells. D: Representative transmission electron microscopy images of CECs in WT and ApoE ${ }^{-/-}$mice fed with SD or high-fat diet (HFD). CEC mitochondria in WT mice fed HFD (WH) and $A p o E^{-/}{ }^{-}$mice fed SD (AS) mice appear swollen with disorganized inner membrane cristae (arrows). Cristae were swollen in or absent from CECs in $\mathrm{ApoE}^{-/-}$mice fed HFD (AH) mice (asterisk) in contrast to the dense and organized cristae of mitochondria in CECs of WS mice. E: The ratio of dysfunctional mitochondria increases in hyperlipidemic mice. Data are expressed as means $\pm \mathrm{SD}(\mathbf{E}) . n=3(\mathbf{A}-\mathbf{E})$. ${ }^{* * *} P<0.001$. Scale bars: $50 \mu \mathrm{m}(\mathbf{A}-\mathbf{C}) ; 0.2 \mu \mathrm{m}$ (D).

hyperlipidemia induces oxidative stress and mitochondrial dysfunction in CECs.

\section{Palmitate Induces Phenotype Changes in Cultured rCECS}

The aqueous humor provides nutrients to the corneal endothelium and helps maintain intraocular pressure. It also represents a valuable sample resource for biomarker analysis in various anterior segment ocular disorders. ${ }^{24,25}$ Lipids in the aqueous humor in Fuchs endothelial corneal dystrophy patients, for example, differ from those in healthy subjects, suggesting that lipid composition in the aqueous humor may affect the function of the corneal endothelium. ${ }^{26}$ An excess supply of fatty acids, such as palmitate, is thought to produce oxidative stress and mitochondrial dysfunction, resulting in lipotoxicity in various tissues, such as liver, heart, and $\beta$ cells. ${ }^{27-29}$ Herein, we investigated the fatty acid levels in aqueous humor from the experimental and control groups and found that the most obvious change was in the level of palmitate, whereas other fatty acids in hyperlipidemia mice did not show constant increase (Figure 5A and Supplemental Figure S3). Compared with WS mice $(3.64 \pm 0.54 \mu \mathrm{mol} / \mathrm{L})$, a onefold increase of palmitate was observed in the aqueous humor of WH mice $(6.41 \pm 1.09$ $\mu \mathrm{mol} / \mathrm{L})$ and $\mathrm{AS}$ mice $(8.55 \pm 4.31 \mu \mathrm{mol} / \mathrm{L})$, with a fivefold increase seen in AH mice $(24.23 \pm 3.22 \mu \mathrm{mol} / \mathrm{L})$ (Figure 5A). Other major fatty acids were also detected in aqueous humor; and it was found that eicosenoic, docosahexaenoic, linolenic, and eicosapentaenoic fatty acids in hyperlipidemia mice did not show a constant increase, such that there were no significant difference between different groups (Supplemental Figure S3).

To further investigate the effect of palmitate on CECs, rCECs were treated with palmitate and tested for lipotoxicity. After 24 hours of treatment with 0 to 1000 $\mu \mathrm{mol} / \mathrm{L}$ palmitate, a dose-dependent decrease in cell viability was observed in the 600 to $1000 \mu \mathrm{mol} / \mathrm{L}$ 
A

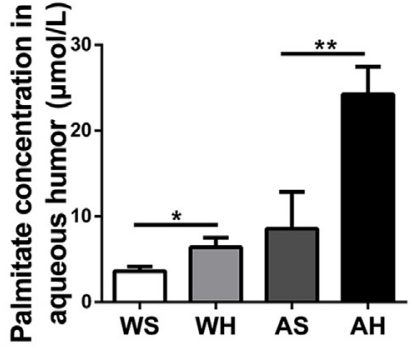

B

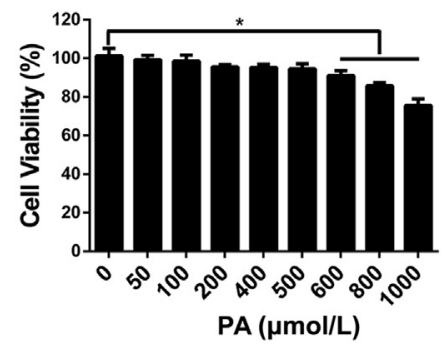

C
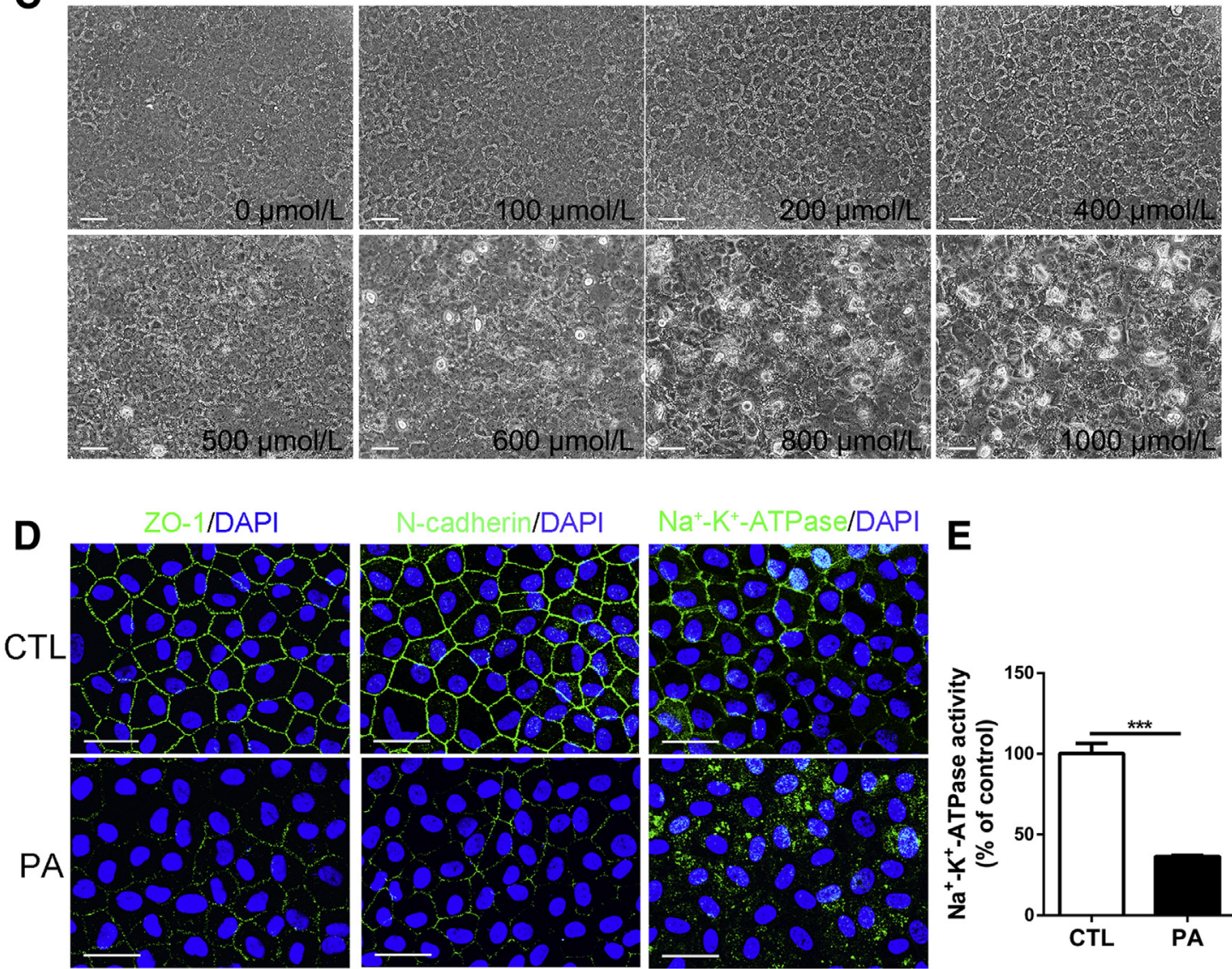

E
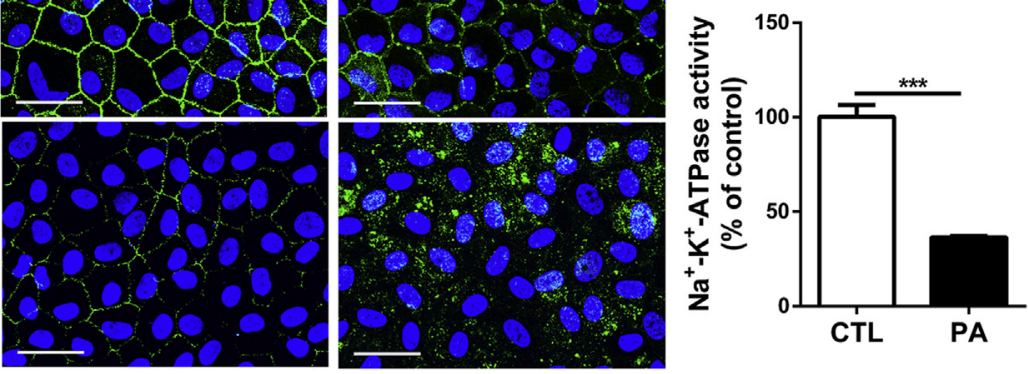

F

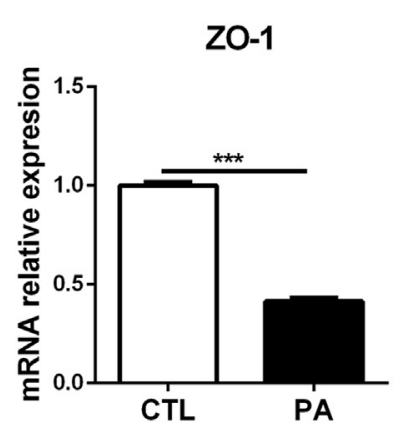

G

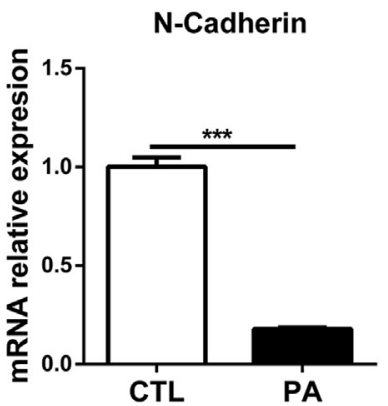

H

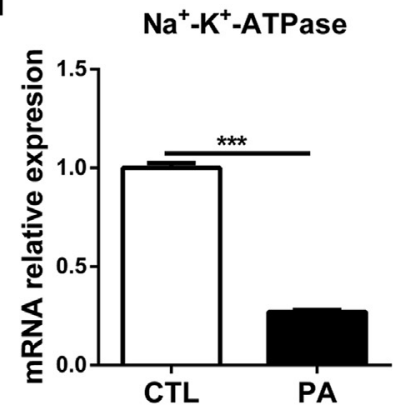

Figure 5 Palmitate (PA) affects tight junction and pump function in cultured rabbit corneal endothelial cells (rCECs). A: Palmitate concentration in aqueous humor is significantly increased in hyperlipidemia mice. B: PA reduces viability of rCECs at concentrations $>600 \mu \mathrm{mol} / \mathrm{L}$. C: Representative images of morphologic changes in palmitate-treated rCECs. D: Representative images of zonula occludens protein 1 (ZO-1), N-cadherin, and Na ${ }^{+}-\mathrm{K}^{+}$-ATPase expression under palmitate treatment. E: Palmitate treatment decreases $\mathrm{Na}^{+}-\mathrm{K}^{+}$-ATPase activity by $60 \%$ compared with the control (CTL) group. F-H: Real-time PCR analysis shows down-regulated gene expression of Z0-1, N-cadherin, and $\mathrm{Na}^{+}-\mathrm{K}^{+}$-ATPase under palmitate treatment. Data are expressed as means \pm SD (A, B, and $\mathbf{E}-\mathbf{H}) . n=3(\mathbf{A}, \mathbf{D}$, and $\mathbf{E}) ; n=5(\mathbf{B}, \mathbf{C}$, and $\mathbf{F}-\mathbf{H}) .{ }^{*} P<0.05,{ }^{*} P<0.01$, and ${ }^{* * *} P<0.001$. Scale bars $=20 \mu \mathrm{m}(\mathbf{C}) ; 50 \mu \mathrm{m}(\mathbf{D})$. AH, ApoE ${ }^{-/-}$mice fed high-fat diet; AS, $A p O E^{-/-}$mice fed standard diet; WH, wild-type mice fed high-fat diet; WS, wild-type mice fed standard diet. 

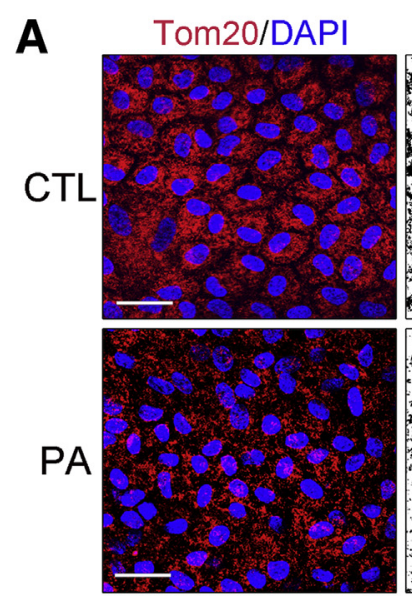

C
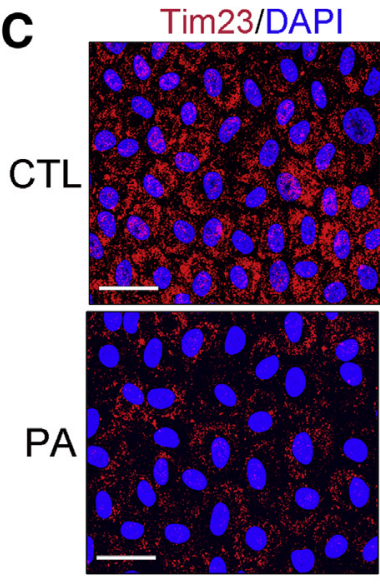

Total particles Continuous structures

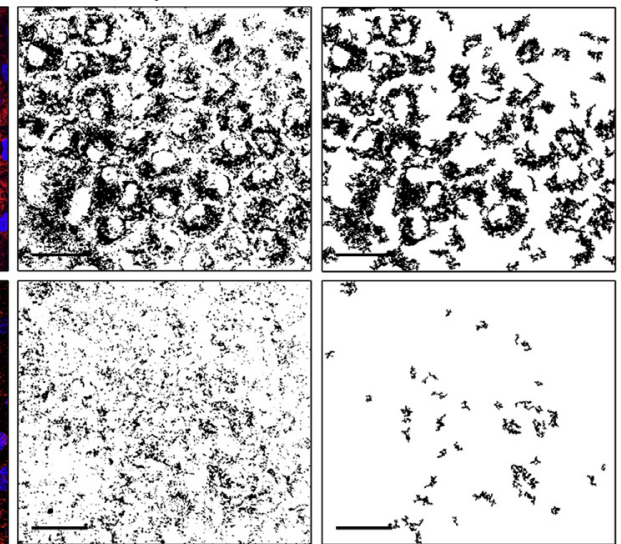

Total particles Continuous structures
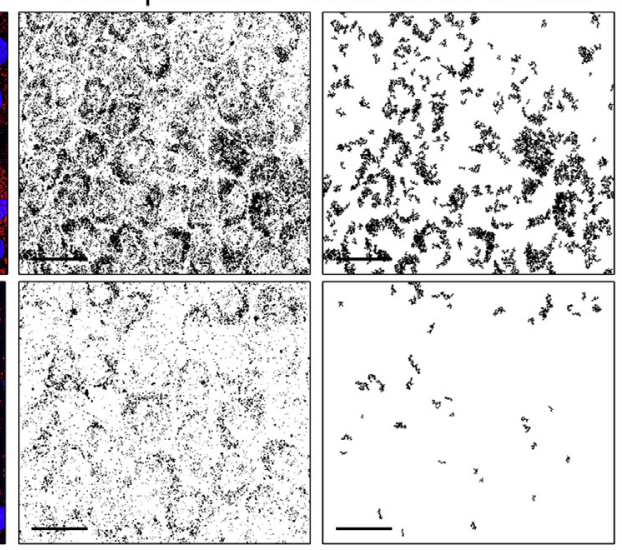

D

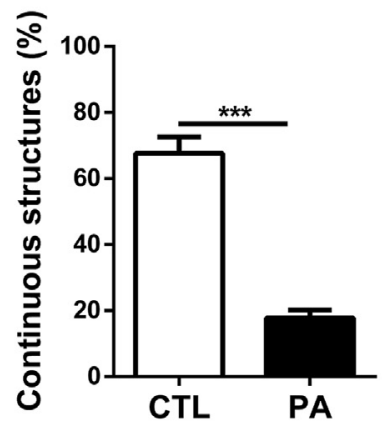

B

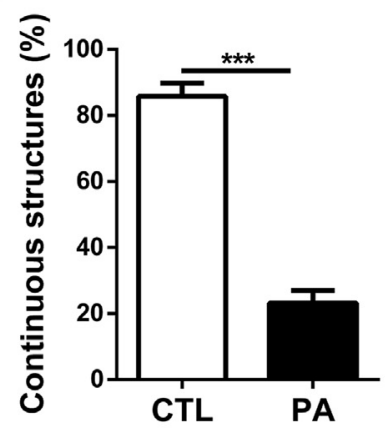

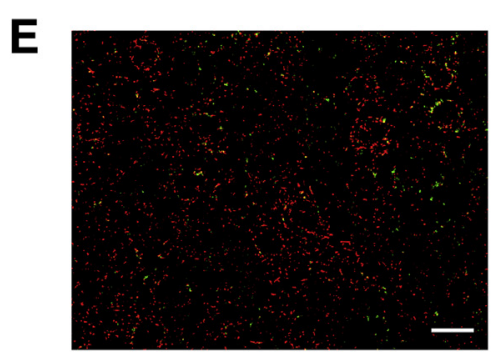

CTL

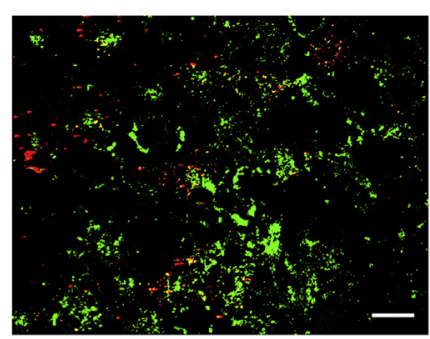

PA
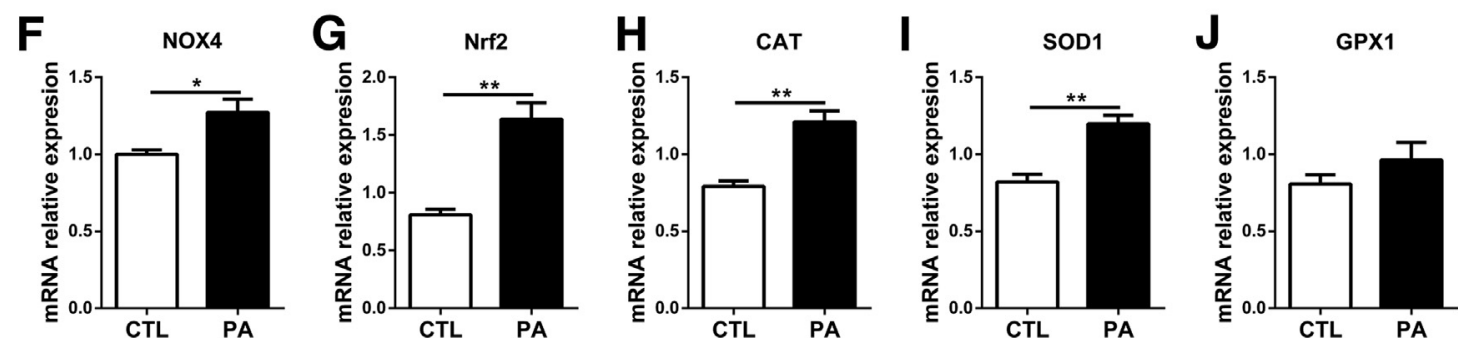

Figure 6 Palmitate (PA) disrupts mitochondria and activates oxidative stress in cultured rabbit corneal endothelial cells. A and C: Immunofluorescence staining of Tom 20 and Tim23. The immunofluorescence of Tom20 and Tim23 was separated, thresholded, filtered, and binarized using ImageJ software version 1.49. B and D: The percentage of total mitochondrial continuous structures decreases under PA treatment. E: Red fluorescence represents the mitochondrial aggregate form of JC-1, indicating intact mitochondrial membrane potential. Green fluorescence represents the monomeric form of JC- 1 , indicating dissipation of mitochondrial transmembrane potential. JC-1 staining exhibits low density of green fluorescence and high density of red fluorescence in control (CTL) group, whereas green fluorescence intensity is increased and red fluorescence intensity is decreased after palmitate treatment. F-J: The mRNA levels of NADPH oxidase 4 (NOX4), nuclear factor erythroid 2-related factor 2 (Nrf2), catalase (CAT), and superoxide dismutase 1 (SOD1) show significant up-regulation in PA treatment group, whereas glutathione peroxidase 1 (GPX1) expression does not show dramatic change. Data are expressed as means \pm SD (B, D, and $\mathbf{F}-\mathbf{J}) . n=3(\mathbf{A}, \mathbf{C}$, and $\mathbf{E}) ; n=5(\mathbf{F}-\mathbf{J}) .{ }^{*} P<0.05,{ }^{*} P<<0.01$, and ${ }^{* *} P<0.001$. Scale bars $=50 \mu \mathrm{m}(\mathbf{A}, \mathbf{C}$, and $\mathbf{E})$. 
concentration range based on a Cell Counting Assay Kit- 8 (Figure 5B). At $500 \mu \mathrm{mol} / \mathrm{L}$, rCECs displayed morphologic changes, such as loss of hexagonal morphology, disordered cell boundaries, and detachment of occasional cells from the culture surface, without a significant decrease in cell viability (Figure 5C). On the basis of this, $500 \mu \mathrm{mol} / \mathrm{L}$ was chosen as the treatment dosage for further investigations. The expression levels of ZO-1, Ncadherin, and $\mathrm{Na}^{+}-\mathrm{K}^{+}$-ATPase under palmitate treatment were significantly disordered and decreased compared with control group, which exhibited relatively integral staining (Figure 5D). $\mathrm{Na}^{+}-\mathrm{K}^{+}$-ATPase activity of cultured rCECs was further determined under palmitate treatment; and consistent with the above immunofluorescence staining findings, palmitate treatment decreased $\mathrm{Na}^{+}-\mathrm{K}^{+}{ }_{-}$ ATPase activity by $60 \%$ compared with the non-palmitate treatment control group (Figure 5E). Meanwhile, the real-time PCR results confirmed that gene expression of ZO-1 (Figure 5F), N-cadherin (Figure 5G), and $\mathrm{Na}^{+}-\mathrm{K}^{+}$-ATPase (Figure 5H) also dramatically decreased after palmitate treatment, providing direct evidence that palmitate can induce structural and functional disruption of CECs.

\section{Palmitate Induces 0xidative Stress Activation and Mitochondrial Dysfunction in Cultured rCECs}

The mitochondrial outer membrane is facilitated with a multiprotein translocase complex that mediates protein import. Tom20, one of the peripheral proteins of the complex, is considered to be a marker for mitochondrial function. ${ }^{30}$ The mitochondrial inner membrane 23 (Tim23) transposase is the major endometrial transposase that mediates the import of essential proteins into the matrix. ${ }^{31}$ Mitochondrial fragmentation is a characteristic hallmark in the pathogenesis of many diseases, such as Alzheimer disease and brain injury. ${ }^{32-34}$ To examine mitochondrial function in rCECs, immunofluorescence staining of Tom 20 and Tim23 was performed, and the segments were further separated, thresholded, filtered, and binarized using Image J software version 1.49 (NIH, Bethesda, MD; https://imagej. nih.gov/ij). Higher densities of mitochondrial total particles and continuous structures were seen in the control group compared with the palmitate-treated rCECs (Figure 6, A-D). To further confirm the effects of palmitate on mitochondria function, JC-1 staining was performed on the cultured rCEC. rCECs under palmitate treatment exhibited obvious green fluorescence with little red fluorescence; this is an indication of the down-regulation of mitochondrial transmembrane potential. In contrast, the rCECs of control group without palmitate treatment emitted bright red fluorescence with little green fluorescence, suggesting normal levels of mitochondrial transmembrane potential (Figure 6E). Collectively, these data indicate that palmitate could disrupt the integrity of mitochondrial structure and cause mitochondrial dysfunctions.
Elevated intracellular levels of reactive oxygen species contribute to pathogenesis of multiple diseases. ${ }^{35}$ To determine oxidative stress activation in rCECs under palmitate treatment, the expression of reactive oxygen species-related genes was analyzed. Real-time PCR revealed that after palmitate treatment, pro-oxidative marker NOX4 (Figure 6F), and oxidative stress-related transcription factor nuclear factor erythroid 2-related factor 2 (Figure 6G) were up-regulated. Meanwhile, the gene expression levels of catalase (Figure 6H), antioxidant superoxide dismutase 1 (Figure 6I), and glutathione peroxidase 1 (Figure $6 \mathbf{J}$ ) were also upregulated, indicating oxidative stress activation in rCECs after palmitate treatment.

\section{Discussion}

The corneal endothelium plays a pivotal role in maintaining corneal transparency through intact cell junctions and a metabolically active pump function. ${ }^{36}$ Damage to corneal endothelial cells beyond a certain threshold can compromise endothelium function, resulting in corneal edema and vision loss. ${ }^{37}$ In humans, corneal endothelial dysfunction is the reason for $>30 \%$ of corneal transplant surgeries. Human corneal endothelial cells remain nonproliferative in vivo, ${ }^{38}$ and damage to CECs results in decompensation of the endothelial function. This study, for the first time, demonstrates the effect of hyperlipidemia on the physiology of CECs. Hyperlipidemia-induced cell junctional damage and reduced pump function of CECs that impacts tissue homeostasis were observed. There were three hyperlipidemia murine models in this study, including $\mathrm{WH}, \mathrm{AS}$, and $\mathrm{AH}$ mice. Corneal arcus was not seen in any of these groups (data not shown), indicating no obvious lipid deposition in the corneal stroma. However, aqueous humor palmitate concentration increased approximately onefold in $\mathrm{WH}$ and AS mice and fivefold in AH mice. This is the first time that aqueous humor lipid concentration has been reported to change in hyperlipidemia. Oil Red O staining further proved that lipid deposition was mainly present in the cell junction area and cytoplasm of CECs, which was similar to changes in vascular endothelial cells under hyperlipidemic condition. ${ }^{39-41}$

In hyperlipidemia mouse models, the expression of tight junction protein ZO-1 and endothelial cell-specific junction protein $\mathrm{N}$-cadherin both decreased, and the protein distribution in the cell border area was also disorganized. It is well known that cell-cell junctions are critical in maintaining cell shape in the corneal endothelial monolayer. $^{42,43}$ In vivo confocal images disclosed morphologic changes in CECs under hyperlipidemic conditions. The percentage of typical hexagonal CECs decreased in mice with hyperlipidemia, and this was highly correlated with the severity of hyperlipidemia in the three different mice models. We speculate that the cellular morphologic change is not only attributed to cell junctional damage during 
hyperlipidemia, but also to the endothelial cell density decrease.

The severity of hyperlipidemia correlated with the decreased CEC number density, and sporadic apoptotic cells were observed in hyperlipidemic mice (Supplemental Figure S4), which may contribute to the decrease of CEC density. These findings are similar to the changes observed in vascular endothelial cells under hyperlipidemic conditions. ${ }^{44,45}$ It is well known that microvilli are instrumental in promoting metabolic cellular activity and are damaged during cytoplasmic lipid accumulation. ${ }^{46,47}$ Herein, we observed a decrease in microvilli in hyperlipidemic mice, and propose that it is an important parameter in CEC dysfunction.

Although these data provide evidence of CEC junction damage and some indication of possible reductions in pump function and CEC number density, corneal edema and corneal thickness changes were not observed in the three hyperlipidemia murine models in the unwounded state. This indicates that overall corneal endothelial function could still be maintained even with the physiological changes reported. As predicted, all the endothelial cryodamage murine models exhibited severe corneal edema after wounding. Interestingly, WS mice almost recovered 1 week after wounding, but the hyperlipidemic groups remained unrecovered after a week, with clear evidence of stromal edema and decreased corneal transparency. This indicates that the wound healing ability of CECs is affected by hyperlipidemia.

Several oxidative stress markers, such as 4-HNE, 8$\mathrm{OHdG}$, and NOX4, were up-regulated in hyperlipidemia mice, contributing to mitochondria change in CECs. Previous studies have shown that abnormal lipid accumulation in cells can induce oxidative stress and mitochondria damage, ${ }^{48,49}$ and our study confirms that this is the case in CECs too. Palmitate is widely used in ex vivo cell culture to investigate the pathophysiology of hyperlipidemia. ${ }^{50}$ In our study, $500 \mu \mathrm{mol} / \mathrm{L}$ palmitate in culture medium induced oxidative stress in vitro, resulting in rCEC junctional damage and cell pump function impairment. We note that the highest aqueous humor palmitate concentration in the animal models - found in AH mice-was $24.23 \mu \mathrm{mol} / \mathrm{L}$, which is much lower than the concentration used in cell culture. The different sensitivity of CECs to palmitate under in vivo and $e x$ vivo condition may be due to chronic accumulation effect of palmitate in the animal model and prominent different compositions between aqueous humor and culture medium.

In summary, our results indicate that hyperlipidemia likely induces oxidative stress and tight junction and pump function damage in CECs, as indicated by the results of our animal model and cell culture studies, suggesting that it may be a risk factor for corneal endothelial dysfunction. Further studies are needed to investigate the association between hyperlipidemia and corneal endothelial decompensation as well as other abnormalities in a clinical setting.

\section{Author Contributions}

J.B., Y.W., J.Y., and W.L. designed research; J.B., Y.W., J.Y., X.C., H.S., H.H., N.J., K.L., L.T., and M.Z. performed the experiments; J.B. and W.L. analyzed the data; J.B., J.M.V., W.L., A.J.Q., Z.L., and Y.C. wrote and revised the manuscript.

\section{Supplemental Data}

Supplemental material for this article can be found at http://doi.org/10.1016/j.ajpath.2019.11.008.

\section{References}

1. Crispin S: Ocular lipid deposition and hyperlipoproteinaemia. Prog Retin Eye Res 2002, 21:169-224

2. Chen H, Miao H, Feng YL, Zhao YY, Lin RC: Metabolomics in dyslipidemia. Adv Clin Chem 2014, 66:101-119

3. Bahmani M, Mirhoseini M, Shirzad H, Sedighi M, Shahinfard N, Rafieian-Kopaei M: A review on promising natural agents effective on hyperlipidemia. J Evid Based Complement Altern Med 2015, 20: 228-238

4. Subramanian S, Chait A: Hypertriglyceridemia secondary to obesity and diabetes. Biochim Biophys Acta 2012, 1821:819-825

5. Li D, Zhang L, Dong F, Liu Y, Li N, Li H, Lei H, Hao F, Wang Y, Zhu Y, Tang H: Metabonomic changes associated with atherosclerosis progression for LDLR(-/-) mice. J Proteome Res 2015, 14: 2237-2254

6. Davis N, Katz S, Wylie-Rosett J: The effect of diet on endothelial function. Cardiol Rev 2007, 15:62-66

7. Koka S, Xia M, Chen Y, Bhat OM, Yuan X, Boini KM, Li PL: Endothelial NLRP3 inflammasome activation and arterial neointima formation associated with acid sphingomyelinase during hypercholesterolemia. Redox Biol 2017, 13:336-344

8. Cimellaro A, Perticone M, Fiorentino TV, Sciacqua A, Hribal ML: Role of endoplasmic reticulum stress in endothelial dysfunction. Nutr Metab Cardiovasc Dis 2016, 26:863-871

9. Zech LA Jr, Hoeg JM: Correlating corneal arcus with atherosclerosis in familial hypercholesterolemia. Lipids Health Dis 2008, 7:7

10. Crispin SM, Barnett KC: Arcus lipoides corneae secondary to hypothyroidism in the Alsatian. J Small Anim Pract 1978, 19: $127-142$

11. Reddy C, Stock EL, Mendelsohn AD, Nguyen HS, Roth SI, Ghosh S: Pathogenesis of experimental lipid keratopathy: corneal and plasma lipids. Invest Ophthalmol Vis Sci 1987, 28:1492-1496

12. Cogan DC, Kuwabara T: Lipid keratopathy and atheroma. Trans Am Ophthalmol Soc 1958, 56:109-119. discussion 109-119

13. Crispin SM: Lipid deposition at the limbus. Eye (Lond) 1989, 3 : 240-250

14. Li S, Zeng XY, Zhou X, Wang H, Jo E, Robinson SR, Xu A, Ye JM: Dietary cholesterol induces hepatic inflammation and blunts mitochondrial function in the liver of high-fat-fed mice. J Nutr Biochem 2016, 27:96-103

15. Lee HS, Nam Y, Chung YH, Kim HR, Park ES, Chung SJ, Kim JH, Sohn UD, Kim HC, Oh KW, Jeong JH: Beneficial effects of phosphatidylcholine on high-fat diet-induced obesity, hyperlipidemia and fatty liver in mice. Life Sci 2014, 118:7-14

16. Ong JM, Zorapapel NC, Rich KA, Wagstaff RE, Lambert RW, Rosenberg SE, Moghaddas F, Pirouzmanesh A, Aoki AM, Kenney MC: Effects of cholesterol and apolipoprotein E on retinal abnormalities in ApoE-deficient mice. Invest Ophthalmol Vis Sci 2001, 42:1891-1900 
17. Sato N, Nakamura M, Chikama T, Nishida T: Abnormal deposition of laminin and type IV collagen at corneal epithelial basement membrane during wound healing in diabetic rats. Jpn J Ophthalmol 1999, 43:343-347

18. Hofker MH, van Vlijmen BJ, Havekes LM: Transgenic mouse models to study the role of APOE in hyperlipidemia and atherosclerosis. Atherosclerosis 1998, 137:1-11

19. van Ree JH, van den Broek WJ, Dahlmans VE, Groot PH, VidgeonHart M, Frants RR, Wieringa B, Havekes LM, Hofker MH Diet-induced hypercholesterolemia and atherosclerosis in heterozygous apolipoprotein E-deficient mice. Atherosclerosis 1994, 111: $25-37$

20. Li C, Dong F, Jia Y, Du H, Dong N, Xu Y, Wang S, Wu H, Liu Z, Li W: Notch signal regulates corneal endothelial-to-mesenchymal transition. Am J Pathol 2013, 183:786-795

21. Chen L, Xie B, Li L, Jiang W, Zhang Y, Fu J, Guan G, Qiu Y: Rapid and sensitive LC-MS/MS analysis of fatty acids in clinical samples. Chromatographia 2014, 77:1241-1247

22. Salvioli S, Ardizzoni A, Franceschi C, Cossarizza A: JC-1, but not DiOC6(3) or rhodamine 123 , is a reliable fluorescent probe to assess delta psi changes in intact cells: implications for studies on mitochondrial functionality during apoptosis. FEBS Lett 1997, 411: $77-82$

23. Monguchi T, Hara T, Hasokawa M, Nakajima H, Mori K, Toh R, Irino Y, Ishida T, Hirata KI, Shinohara M: Excessive intake of trans fatty acid accelerates atherosclerosis through promoting inflammation and oxidative stress in a mouse model of hyperlipidemia. J Cardiol 2017, 70:121-127

24. Klenkler B, Sheardown H: Growth factors in the anterior segment: role in tissue maintenance, wound healing and ocular pathology. Exp Eye Res 2004, 79:677-688

25. Maatta M, Tervahartiala T, Harju M, Airaksinen J, AutioHarmainen H, Sorsa T: Matrix metalloproteinases and their tissue inhibitors in aqueous humor of patients with primary open-angle glaucoma, exfoliation syndrome, and exfoliation glaucoma. J Glaucoma 2005, 14:64-69

26. Cabrerizo J, Urcola JA, Vecino E, Melles G: Changes in lipidomic profile of aqueous humour in Fuchs endothelial dystrophy. Acta Ophthalmol 2017, 95:727-732

27. Wende AR, Abel ED: Lipotoxicity in the heart. Biochim Biophys Acta 2010, 1801:311-319

28. Slawik M, Vidal-Puig AJ: Lipotoxicity, overnutrition and energy metabolism in aging. Ageing Res Rev 2006, 5:144-164

29. McGavock JM, Lingvay I, Zib I, Tillery T, Salas N, Unger R, Levine BD, Raskin P, Victor RG, Szczepaniak LS: Cardiac steatosis in diabetes mellitus: a $1 \mathrm{H}$-magnetic resonance spectroscopy study. Circulation 2007, 116:1170-1175

30. Abe Y, Shodai T, Muto T, Mihara K, Torii H, Nishikawa S, Endo T, Kohda D: Structural basis of presequence recognition by the mitochondrial protein import receptor Tom20. Cell 2000, 100:551-560

31. Demishtein-Zohary K, Marom M, Neupert W, Mokranjac D, Azem A: GxxxG motifs hold the TIM23 complex together. FEBS J 2015, 282:2178-2186

32. Otera $\mathrm{H}$, Ishihara N, Mihara K: New insights into the function and regulation of mitochondrial fission. Biochim Biophys Acta 2013 , $1833: 1256-1268$

33. Wang R, Dong Y, Lu Y, Zhang W, Brann DW, Zhang Q: Photobiomodulation for global cerebral ischemia: targeting mitochondrial dynamics and functions. Mol Neurobiol 2019, 56:1852-1869
34. Tucker LD, Lu Y, Dong Y, Yang L, Li Y, Zhao N, Zhang Q: Photobiomodulation therapy attenuates hypoxic-ischemic injury in a neonatal rat model. J Mol Neurosci 2018, 65:514-526

35. Ponferrada A, Caso JR, Alou L, Colon A, Sevillano D, Moro MA, Lizasoain I, Menchen P, Gomez-Lus ML, Lorenzo P, Cos E, Leza JC, Menchen L: The role of PPARgamma on restoration of colonic homeostasis after experimental stress-induced inflammation and dysfunction. Gastroenterology 2007, 132:1791-1803

36. Roy O, Leclerc VB, Bourget JM, Theriault M, Proulx S: Understanding the process of corneal endothelial morphological change in vitro. Invest Ophthalmol Vis Sci 2015, 56:1228-1237

37. Zavala J, Lopez Jaime GR, Rodriguez Barrientos CA, ValdezGarcia J: Corneal endothelium: developmental strategies for regeneration. Eye (Lond) 2013, 27:579-588

38. Parekh M, Ferrari S, Sheridan C, Kaye S, Ahmad S: Concise review: an update on the culture of human corneal endothelial cells for transplantation. Stem Cells Transl Med 2016, 5:258-264

39. Stoletov K, Fang L, Choi SH, Hartvigsen K, Hansen LF, Hall C, Pattison J, Juliano J, Miller ER, Almazan F, Crosier P, Witztum JL, Klemke RL, Miller YI: Vascular lipid accumulation, lipoprotein oxidation, and macrophage lipid uptake in hypercholesterolemic zebrafish. Circ Res 2009, 104:952-960

40. Milosavljevic D, Griglio S, Le Naour G, Chapman MJ: Preferential reduction of very low density lipoprotein-1 particle number by fenofibrate in type IIB hyperlipidemia: consequences for lipid accumulation in human monocyte-derived macrophages. Atherosclerosis 2001, 155:251-260

41. Stehbens WE: The role of lipid in the pathogenesis of atherosclerosis. Lancet 1975, 1:724-727

42. Fischbarg J, Diecke FP, Iserovich P, Rubashkin A: The role of the tight junction in paracellular fluid transport across corneal endothelium: electro-osmosis as a driving force. J Membr Biol 2006, 210:117-130

43. Vassilev VS, Mandai M, Yonemura S, Takeichi M: Loss of N-cadherin from the endothelium causes stromal edema and epithelial dysgenesis in the mouse cornea. Invest Ophthalmol Vis Sci 2012, 53: 7183-7193

44. Birck MM, Saraste A, Hyttel P, Odermarsky M, Liuba P, Saukko P, Hansen AK, Pesonen E: Endothelial cell death and intimal foam cell accumulation in the coronary artery of infected hypercholesterolemic minipigs. J Cardiovas Transl Res 2013, 6:579-587

45. Sima AV, Stancu CS, Simionescu M: Vascular endothelium in atherosclerosis. Cell Tissue Res 2009, 335:191-203

46. Lange K: Fundamental role of microvilli in the main functions of differentiated cells: outline of an universal regulating and signaling system at the cell periphery. J Cell Physiol 2011, 226:896-927

47. Gov NS: Dynamics and morphology of microvilli driven by actin polymerization. Phys Rev Lett 2006, 97:018101

48. Sinha K, Das J, Pal PB, Sil PC: Oxidative stress: the mitochondriadependent and mitochondria-independent pathways of apoptosis. Arch Toxicol 2013, 87:1157-1180

49. Matsuzawa N, Takamura T, Kurita S, Misu H, Ota T, Ando H, Yokoyama M, Honda M, Zen Y, Nakanuma Y, Miyamoto K, Kaneko S: Lipid-induced oxidative stress causes steatohepatitis in mice fed an atherogenic diet. Hepatology 2007, 46:1392-1403

50. Du JY, Yuan F, Zhao LY, Zhu J, Huang YY, Zhang GS, Wei Y, Liu Y, Yi Q, Tu YS, Zhong X, Sun FY, Sun HS, Guan YY, Chen WL, Wang GL: Suppression of Kv1.5 protects against endothelial apoptosis induced by palmitate and in type 2 diabetes mice. Life Sci 2017, 168:28-37 